\title{
Impact of three-dimensional printing in surgical planning of congenital heart disease
}

\author{
Efectos de la impresión 3D en la planificación quirúrgica de las cardiopatías congénitas
}

Roberto Cano-Zárate ${ }^{*}$, Erick K. Hernández-Barajas², Helios H. Hernández-Barajas², Aloha Meave-González ${ }^{1}$, and Nilda Espínola-Zavaleta ${ }^{3}$

${ }^{1}$ Department of Magnetic Resonance, Instituto Nacional de Cardiología "Ignacio Chávez;" 23DMJMAKERS Medical Printing Laboratory; ${ }^{3}$ Department of Nuclear Cardiology, Instituto Nacional de Cardiología "Ignacio Chávez," Mexico City, Mexico

\begin{abstract}
Introduction: Congenital heart disease makes up for $30 \%$ of all congenital anomalies. The prevalence is $8 / 1000$ live newborns, without predominance of gender. Imaging methods such as echocardiography, angiography, computed tomography, or magnetic resonance imaging must be routinely used in congenital heart disease. The mentioned methods can provide virtual reconstructions in volumetric reconstruction or in three-dimensional (3D), but only 3D-printed heart models can provide real $3 D$ tactile replicas of cardiac anatomy. Objective: The objective of the study was to make 3D printed heart models to provide real $3 D$ tactile replicas of the cardiac anatomy that allows a detailed visualization from all possible perspectives, either of extracardiac or intracardiac structures. Methods: This information is useful for surgical decision-making, especially in patients with complex cardiac defects. DICOM edited in a software package "3D slicer 4.3" and exported for printing in file format (.stl). Results and conclusions: With $3 D$ printing, the intracardiac and extracardiac anatomy can be evaluated in detail with real-scale cardiac models of the patient, avoiding unexpected findings. This technique is very useful especially in complex congenital heart defects, since it allows precise planning of the surgical procedure.
\end{abstract}

Key words: Congenital heart disease. Cardiac imaging. Three-dimensional printing. Surgical planning.

\section{Resumen}

Introducción: Los defectos cardíacos congénitos constituyen el 30\% de todas las anomalías congénitas. La prevalencia es de 8/1,000 recién nacidos vivos, sin predominio de género. Para una planificación quirúrgica óptima es esencial una evaluación precisa de la anatomía en los defectos cardíacos congénitos. Las modalidades de imagen como el ecocardiograma, la angiografía por cateterismo cardíaco, la tomografía computarizada (TC) o la resonancia magnética (RM) se utilizan de forma regular para el diagnóstico de las cardiopatías congénitas. Estos métodos pueden proporcionar reconstrucciones virtuales en reconstrucción volumétrica o 3D, pero no réplicas táctiles reales de la anatomía cardíaca. Objetivo: Realizar modelos de corazón impresos en 3D con la finalidad de proporcionar réplicas táctiles $3 D$ reales de la anatomía cardíaca para visualizar de forma detallada todas las perspectivas posibles de las estructuras extracardíacas o intracardíacas. Métodos: Los datos de la imagen se obtuvieron en formato DICOM, se editaron en el paquete de software "3D slicer 4.3" y se exportaron para la impresión en formato de archivo (.stl). Resultados y conclusiones: Con la impresión 3D se puede evaluar de forma

Correspondence:

${ }^{*}$ Roberto Cano-Zárate

E-mail: rcanoz@gmail.com
Date of reception: 11-12-2019

Date of acceptance: 03-03-2020

DOI: $10.24875 /$ ACME.M21000170
Available online: $25-05-2021$

Arch Cardiol Mex (Eng). 2021;91(1):1-6 www.archivoscardiologia.com 2604-7063 / @ 2020 Instituto Nacional de Cardiología Ignacio Chávez. Published by Permanyer. This is an open access article under the CC BY-NC-ND license (http://creativecommons.org/licenses/by-nc-nd/4.0/). 
detallada la anatomía intracardíaca y extracardíaca con modelos cardíacos en tiempo real. Esta técnica es de gran utilidad, sobre todo en los defectos cardíacos congénitos complejos, ya que permite hacer una planificación precisa del procedimiento quirúrgico.

Palabras clave: Cardiopatías congénitas. Imagen cardiovascular. Impresión 3D. Planeación quirúrgica.

\section{Introduction}

Since ancient times, knowing the inside the human body has been attempted, but only until the time of the Greeks were the first dissections performed, based on the scientific method. In 1501, Leonardo da Vinci showed a great description of the cardiac anatomy and the great vessels, under a scientific order, in his work The Heart and its Blood Vessels.

Before the evolution of imaging methods, sometimes it was necessary to open the body and explore it to establish the cause of disease. With the evolution of non-invasive imaging methods, anatomy has been determined with higher accuracy.

Congenital heart defects constitute $30 \%$ of all congenital anomalies. The prevalence is $8 / 1000$ live births, without gender predominance ${ }^{1}$. Accurate anatomic evaluation in congenital heart disease is essential to establish optimal surgical planning. Imaging modalities, such as echocardiography, cardiac catheterization and coronary angiography, computed tomography (CT), or magnetic resonance imaging (MRI), are systematically used in this indication. However, these methods can be insufficient to obtain accurate images of cardiovascular anatomical relationships in complex congenital heart diseases ${ }^{2}$.

These methods can project virtual reconstructions in volumetric reconstruction, but only three-dimensional (3D)-printed heart models based on data obtained by CT or MRI allow generating real 3D tactile replicas of heart anatomy with the benefit of detailed visualization from all possible perspectives ${ }^{2,3}$.

This information is useful for making surgical decisions and indicates the optimal approach for each patient, especially in the presence of some complex alteration. Therefore, the use of 3D heart models makes it possible to detect unexpected findings, particularly in rare or complex congenital heart defects ${ }^{2,3}$.

\section{Methods}

Patients in whom the medical surgical team established the need to specify the anatomy to optimize surgical planning were selected. Congenital heart disease imaging analysis was based on the segmental sequential system, by means of multiplanar slices (Fig. 1), and for demonstration purposes, volumetric, or 3D reconstructions were performed (Fig. 2) in medical-surgical and academic sessions.

The images were obtained from CT or MRI, and the imaging data were stored in DICOM format. The software packages " $3 \mathrm{D}$ slicer 4.3" and "Meshmixer" were used to process the DICOM data, and to visualize and edit the images ${ }^{4}$.

The study was carried out in a CT or MRI equipment and stored in DICOM language. For image editing, the region of interest (ROI) was selected, and surrounding tissues were removed. After the ROI extraction, the surface of the model was edited, and data were stored in stereolithographic archive format with the impression of the heart model ${ }^{4}$. Models were printed on a 1:1 scale (Fig. 3) or, for academic or demonstrative purposes, on a larger-than-real scale in rigid corn biopolymeric material. The printers that were used for these models were Wanhao i3 and Wanhao $5 \mathrm{~s}$. Printing time was 5-8 $\mathrm{h}$ per piece. Approximate cost of each 3D print was 7000 Mexican pesos.

\section{Results}

Cases in which the site of interest was extracardiac vascular structures and intracardiac anatomy were analyzed.

Patient 1. Seventeen-year-old male patient presented with a long-standing history of headache and dizziness. Physical examination revealed systemic arterial hypertension in the upper limbs and decreased pulses in pelvic limbs. Doppler echocardiogram showed distal aortic arch flow acceleration, without the narrowest site being visualized, which was indicative of coarctation of aorta. CT showed coarctation of the aorta immediately distal to the left subclavian artery with supra-aortic vessels dilatation and marked collateral circulation, with transverse aortic arch measurements within normal limits (Fig. 4). In view of the analysis of coarctation by tomography and the 3D piece, interventional treatment was indicated with bare-metal stent placement. 


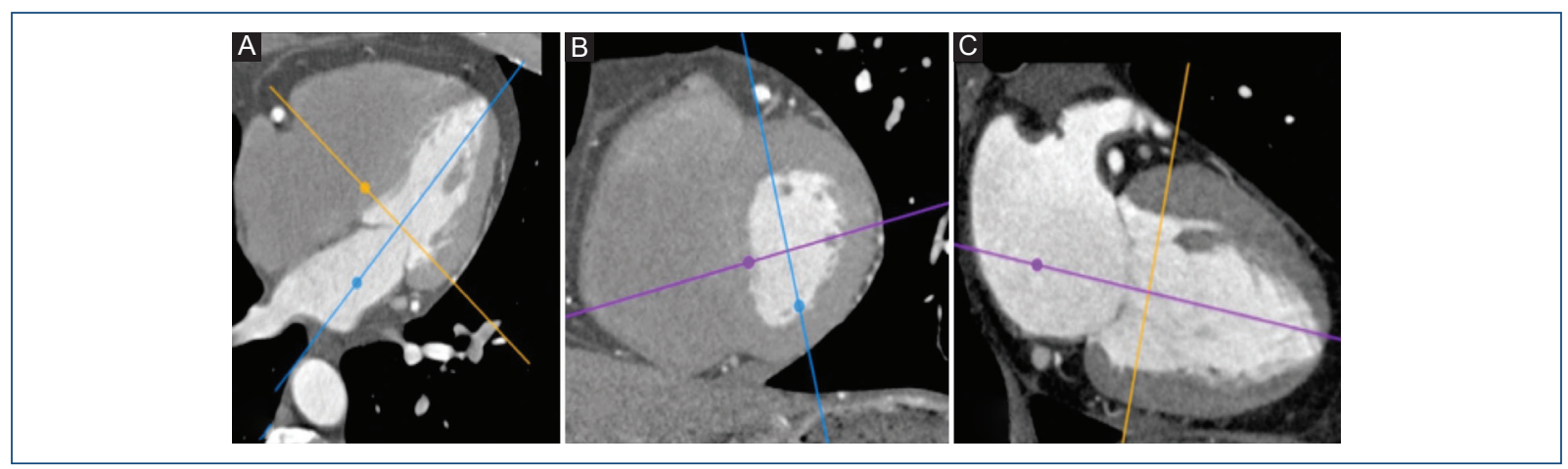

Figure 1. Multiplanar slice CT. Congenital heart disease analysis in different sections. A: four chambers; B: short axis; C: two left chambers.

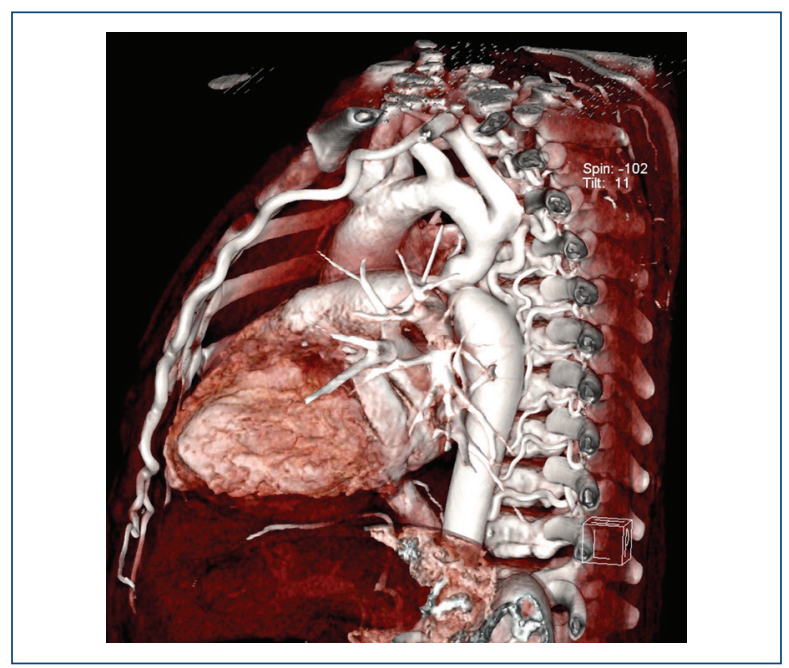

Figure 2. CT with volumetric reconstruction or 3D sagittal visualization. Coarctation of aorta with evident collateral circulation.

Patient 2. One-year-old female patient with community-acquired pneumonia and failed extubation diagnosis. The echocardiogram outlined a dilated pulmonary artery trunk and non-assessable pulmonary branches. CT showed the dilated pulmonary artery trunk with anterior and right trajectory with regard to the trachea, and the left pulmonary artery surrounded the trachea from behind to form a vascular ring (pulmonary sling) with secondary stenosis of the trachea (Fig. 5). The operation consisted of the left pulmonary branch section and anastomosis of this branch with the trunk of the pulmonary artery, anterior to the trachea.

Patient 3. One-month-old male patient diagnosed with type 1 truncus arteriosus, four-leaflet trunk valve,

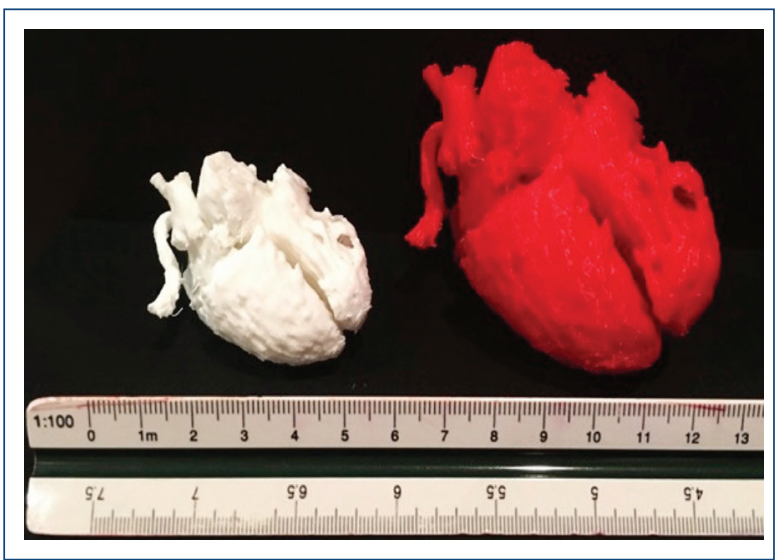

Figure 3. 3D printed models. Left, 1:1 scale image of a patient with a pulmonary vascular ring. Right, 1.5:1 scale image.

noticeably short pulmonary artery trunk with immediate emergence of pulmonary branches, which had a crossed origin; the left branch origin was superior in relation to right branch origin; the left branch was projected straight toward the ipsilateral hemothorax; and the other branch to the right in a plane posterior to the truncus arteriosus. Corrective operation was ventricular septal defect closure with pericardial patch and right ventricle flow redirection to the pulmonary arteries through a synthetic material tube.

Patient 4. Twelve-year-old male patient with diagnosis of double-outlet right ventricle with ventricular septal defect unrelated to great vessels. Echocardiography, invasive angiography, and multiplanar tomography imaging did not allow defining the relationship of ventricular septal defect with the great vessels for patch 


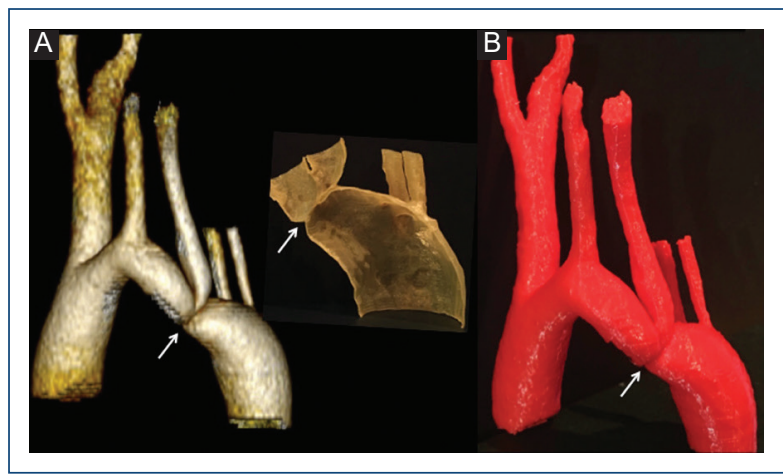

Figure 4. Aortic arch 3D models revealing coarctation of aorta distal to the left subclavian artery (white arrow). A: computed tomography; B: 3D printed model.

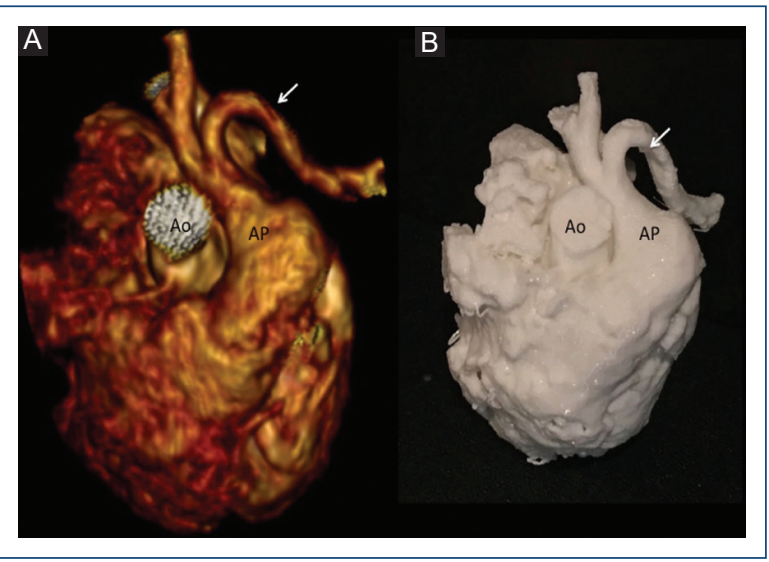

Figure 5. 3D models showing the elongated pulmonary artery trunk with anterior and right direction with regard to the trachea; the left pulmonary artery surrounds the trachea from behind and forms a vascular ring (pulmonary sling, white arrow) with secondary stenosis of the trachea. A: computed tomography; B: 3D printed model.

placement and flow redirection. The tomography-based 3D printed piece was reviewed in a medical-surgical session (Fig. 6), where the ventricular septal defect was found to be related to the aorta rather than to the pulmonary artery.

Patient 5. Ten-year-old male patient diagnosed with unrelated double-outlet right ventricle. Even with the lack of relationship, the aorta was closer to the ventricular septal defect. However, invasive angiography indicated that the flow drifted towards the pulmonary artery. The 3D printing piece was obtained from magnetic resonance images. Higher ventricular septal defect relationship was observed with the aorta with the presence of subaortic infundibular muscle, and for this reason, flow to the aorta was restricted and flow to the pulmonary artery was favored. In surgical planning, closing the ventricular septal defect with pericardial patch and directing the flow of the left ventricle to the aorta was decided. A tube with valve was placed with right ventricle to pulmonary artery trunk anastomosis.

\section{Discussion}

3D printers can produce identical or scale copies of the heart and great vessels based on data obtained from CT or MRI. Patients with congenital heart disease with complex spatial anatomical relationships are the most suitable for $3 \mathrm{D}$ printing, based on the obtained images.

The use of 3D-printed pieces demonstrates better spatial orientation of anatomy and facilitates surgical or interventional procedures and modifies surgical time shortening, as well as patient morbidity and mortality. To determine intracardiac anatomy, 3D printing has shown benefits especially in structural conotruncal heart defects, such as double-outlet right ventricle, in which accurate understanding of the anatomy and structural relationships reflects the success of the repair as, for example, ventricular septal defect relationship with the great vessels (subpulmonary communication, subaortic communication, and unrelated or doubly related) $)^{5,6}$.

3D-printed models of cardiovascular anomalies can also be used as an invaluable teaching tool for pediatric cardiologists and surgeons in training and medical students, since some rare structural alterations can be reproduced and distributed to different centers of the country?.

It is also highly useful in the correction of aortic arch alterations, which can cause obstruction of the supra-aortic vessels when a stent is introduced. 3D impressions of the aortic arch allow measuring stent size, length, and site of release. Models can be radio-opaque and be seen in fluoroscopy without the need to use contrast material, and thus be measured with the method used for in vivo stent placement ${ }^{8}$.

Models can be manufactured with flexible materials, with different textures to replicate valve devices, for percutaneous procedures, with flexibility that is close to that of the real valve apparatus, which reduces complications when choosing the technique and the ideal 


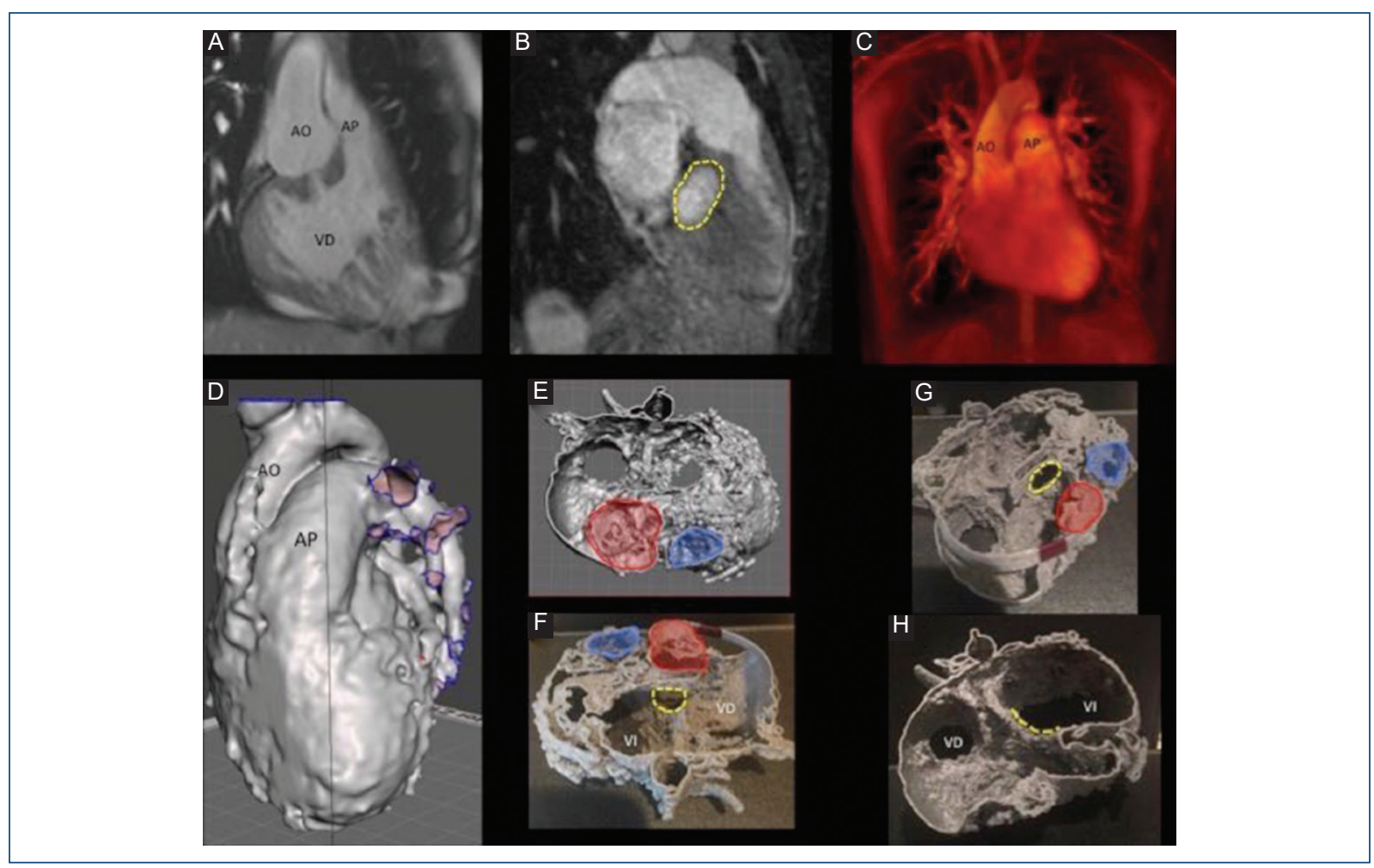

Figure 6. 3D models of a double-outlet right ventricle based on magnetic resonance imaging: A: double-outlet right ventricle with double infundibulum. B: ventricular septal defect more closely related to the aorta. C: double-outlet right ventricle volumetric reconstruction. D: stereolithographic file format volumetric reconstruction before printing. E-H: 3D printed model demonstrating a double-outlet right ventricle with greater intracavitary characterization of the great vessels spatial relationship and higher relationship of the aorta with the ventricular septal defect. Ao: aorta; AP: pulmonary artery; VD: right ventricle; VI: left ventricle.

material for the procedure, with trial and error in the 3D-printed model. In the future, the material will be improved to more accurately reproduce the texture of normal and diseased valves, as well as tendinous cords and areas of greater hardness, which will improve effectiveness of the procedure ${ }^{9}$.

$3 \mathrm{D}$ printing and $3 \mathrm{D}$ rendering are useful tools for understanding congenital heart disease. However, this modality has some limitations related to the subjectivity whereby congenital heart disease is perceived at the time of modeling, which is why, currently, it is only recommended as an auxiliary tool to make surgical decisions; improving 3D acquisition, processing, and manipulation techniques are still necessary to advance and turn it into the only diagnostic and therapeutic tool $^{10}$. Further studies are required to provide more clinical evidence of 3D printing effectiveness and make this method the main one for making therapeutic decisions.

\section{Conclusions}

3D printing is an efficacious method for the study of congenital heart disease. The brain is adapted to recognize and move a in 3D space. In contrast, the eyes are at disadvantage when exploring a body in two dimensions, that is, a multiplanar reconstruction, and they must strive more to transform $2 \mathrm{D}$ images into a 3D image in the mind. With a 3D model, which outlines anatomical relationships and distances, it is possible to improve knowledge about the structure and to provide a more accurate therapeutic approach.

$3 \mathrm{D}$ printing has notable effects on congenital heart disease corrective planning, given that it allows anatomical relationships to be known with higher accuracy than the 2D method.

It is advisable to continue the 3D printing studies to accumulate more clinical evidence on the effectiveness of this method and transforming it into the main tool for therapeutic indications. 


\section{Funding}

This research has not received specific aid from public or commercial sector agencies, or non-profit entities.

\section{Conflicts of interest}

None.

\section{Ethical disclosures}

Protection of human and animal subjects. The authors declare that the procedures that were followed adhered to the ethical standards of the responsible human experimentation committee and were in agreement with the World Medicinal Association and the Declaration of Helsinki.

Confidentiality of data. The authors declare that they have followed the protocols of their work center on the publication of patient data.

Right to privacy and informed consent. The authors declare that no patient data appear in this article.

\section{References}

1. Attie F, Calderón Comenero J, Zabal Cerdeira C, Buendía Hernández A Cardiología Pediátrica. 2da ed. Edit. Panamericana, 2013.

2. Schmauss D, Haeberle S, Hagl C, Sodian R. Three-dimensional printing in cardiac surgery and interventional cardiology: a single-centre experience. Eur J Cardiothorac Surg. 2015;47(6):1044-1052.

3. Mitsouras D, Liacouras P, Imanzadeh A, Giannopoulos AA, Cai T, Kumamaru KK, et al. Medical 3D printing for the radiologist. Radiographics 2015;35(7):1965-88.

4. Fedorov A, Beichel R, Kalpathy Cramer J, Finet J, Fillion Robin JC, Pujol S, et al. 3D Slicer as an image computing platform for the Quantitative Imaging Network. Magn Reson Imaging. 2012;30(9):1323-1341.

5. Dydynski PB, Kiper C, Kozik D, Keller BB, Austin E, Holland B. Three-dimensional reconstruction of intracardiac anatomy using CTA and surgical planning for double outlet right ventricle: early experience at a tertiary care congenital heart center. World J Pediatr Congenit Heart Surg. 2016;7(4):467-474

6. Mahle WT, Martínez R, Silverman N, Cohen MS, Anderson RH. Anatomy, echocardiography, and surgical approach to double outlet right ventricle. Cardiol Young 2008;18:39-51

7. Costello JP. Incorporating three-dimensional printing into a simulation based congenital heart disease and critical care training curriculum, for resident physicians. Congenit Heart Dis. 2015;10:185-190.

8. Valverde I, Gómez G, Coserria JF, Suárez-Mejías C, Uribe S, Sotelo J, et al. 3D printed models for planning endovascular stenting in transverse aortic arch hypoplasia. Catheter Cardiovasc Interv. 2015;85: 1006-1012.

9. Vukicevic M, Puperi DS, Jane Grande-Allen K, Little SH. 3D printed modeling of the mitral valve for catheter-based structural interventions. Ann Biomed Eng. 2017:45(2):508-519.

10. Batteux C, Haidar MA, Bonnet D. 3D-printed models for surgical planning in complex congenital heart diseases: a systematic review. Front Pediatr. 2019;7:23.doi: 10.3389/fped.2019.00023. 